\title{
The Concept of Islamic Dynamic Stochastic General Equilibrium Method in the Financial Theme
}

\author{
Ehsan Rasoulinezhad ${ }^{*}$ \\ Faculty of Economics, University of Economic Sciences, Tehran, Iran
}

\begin{abstract}
Dynamic Stochastic General Equilibrium (DSGE) method is one of the newest subsections of general equilibrium theory in economy which can be used in many economical fields. This article fundamentally presents the concept of this method in combination with Islamic principles in the financial theme. Moreover a conceptual model is designed through the Interpretive Structural Model (ISM). The results of this paper show the structure of DSGE method in the financial theme with Islamic concepts which can be so useful for researchers and decision makers. The crucial implication of this research would be using Islamic DSGE for Islamic nations with specific related variables.
\end{abstract}

Keywords: dynamic models, Islamic principles, interpretive structural model, financial theme

\section{Introduction}

The DSGE is a subsection of general equilibrium theory and obviously its analysis can be used in the macroeconomic fields. The DSGE methodology attempts to explain aggregate economic phenomena, such as economic growth, business cycles, and the effects of monetary and fiscal policies, on the basis of macroeconomic models derived from microeconomic principles. These days the performances of this method are so vast, for instance many organizations, especially central banks in recent years, try to present their economic outlook and policy strategies to the public in a more formal way using DSGE method. This basic research takes a view that the Dynamic Stochastic General Equilibrium (DSGE) can be designed through the Islamic principles in the financial theme. The paper investigates this fact using the Interpretive Structural Model (ISM) which can compare various parts of our micro foundations and distinct their levels in our final model.

Besides these facts about the DSGE, we see the new concept of economics namely "Islamic Economics" or "Islamic Economic System" (Nienhaus, 2010) which identifies and promotes an economic order that conforms to Islamic scripture and traditions. This concept introduces new issues in economics framework (Musai, 2011). For example, Islam promotes a market free from interferences such as price fixing and hoarding. Government intervention, however, is tolerated under specific circumstances or Islam accepts

*Email: erasolinejad@gmail.com markets as the basic coordinating mechanism of the economic system.

Islamic teaching holds that the market, given perfect competition (Azid, 2010) and allows consumers to obtain desired goods and producers to sell their goods at a mutually acceptable price. According to these dimensions, it is useful to apply them in the DSGE model which is used in the financial theme like capital or money markets. But it needs a logically method that here ISM model will be used.

The implication of this research would be in using dynamic models in Islamic societies. If researchers want to model an Islamic economy, they should design it with correct specifications which can proof any errors. Up to now, this approach hasn't considered by researchers. For instance, utility function of a representative household assumed similar whether in Islamic societies or non- Islamic societies in former researches.

\section{Empirical Researches}

\section{Researches about Islamic economics}

Fahim khan (1984) developed the macro consumption function in an Islamic framework. He investigated the saving of Islamic economics and its effects on growth through some mathematical equations. In an empirical research in 2006, Hadavinia, tried to research the structural theoretical basis by adopting a logical method. Musai (2010) in his research presented eight reasons for necessity of currency devaluation compensation. Based on the findings, currency 
devaluation compensation is far from definition of usury and it should be compensated necessarily. Ahmadali (2010) analyzed the cooperative economics with capitalist and Islamic economics through a descriptive method and it was determined that cooperative economics has basic differences with the economy of the capitalist system. Garas in 2012 indicated the conflicts of interest inside the Shari'a supervisory board in the Islamic financial institutions. He used a questionnaire and tested data by OLS method. Abduh and Azma (2012) investigated Islamic banking and economic growth in the Indonesia. He used quarterly data (2003-2010) through ARDL method. The results demonstrate a significant relationship in short run and long run periods between Islamic financial development and economic growth.

\section{Researches about the DSGE method}

Taghavi and Safarzadeh (2009) calculated optimum rate of money growth in New Keynesian DSGE framework for Iran economy. Simulation results demonstrated that Friedman's rule is not supported in Iran economy. Gerali et al. (2010) presented the role of credit supply factors in business cycle fluctuations. They introduced an imperfectly competitive banking sector in to a DSGE model with financial frictions. The result showed an unexpected destruction of bank capital has a substantial impact on the real economy.

Villa and Yang (2011) investigated the financial intermediaries in an estimated DSGE model for the United Kingdom. The paper indicated that banking sector shock seems to play an important role in explaining the UK business cycle. Motevaseli et al., (2011) applied a New Keynesian DSGE for an oil exporting country. Impulse response functions of shocks show that non oil output increase in response to productivity. Caldara et al., (2012) computed DSGE models with recursive preferences and stochastic volatility. They found perturbation methods are an attractive approach for computing this class of problems.

\section{Definitions}

\section{DSGE method}

DSGE method aims to describe the behavior of the economy as a whole by analyzing the interaction of many microeconomic decisions in two different schools; (i) New Keynesian school and; (ii) Real business cycle school that these two schools have some specific assumptions.

The most decisions considered in the DSGE models correspond to some of the main quantities studied in macro economics, such as consumption, saving, investment, labor demand and supply. The decision-makers in this model, often called 'agents', may include households, business firms, and possibly others, such as governments or central banks.

\section{Islamic economics approach}

Islamic economics is rooted perfectly in Islam's particular worldview and derives its value-premises from the ethic-social teachings of the Quran and Sunnah. Islamic approach insists that human nature, motivation, and work must reflect the ethical convictions of Islam so this approach of economy is part of the religion of Islam which covers the various branches of life (Warde, 2000).

\section{Financial Theme}

Financial theme is the specific system in an economy which contains various fields like money, capital, bond, loans and so on. Finance measures the risks vs. profits and gives an indication of whether the investment is good or not. Modeling the financial theme of a country can be a strong way of making decision that causes upward sloping curve of economic growth in that country.

\section{ISM method}

Interpretive Structural Modeling was first proposed by Warfield in 1973 to analyze the complex socioeconomic systems. ISM is a computer-assisted learning process that enables individuals or groups to develop a map of the complex relationships between the many elements involved in a complex situation. The basic idea in this field is to use experts' practical experience and knowledge to decompose a complicated system into several sub-systems (elements) and construct a multilevel structural model.

\section{Methodology}

Attempts to formulate models capable of analyzing and explaining the Islamic principles in DSGE method have taken a number of different notes. A common note is to focus on Islamic utility function besides DSGE method. These elements are mixed through ISM. Our conceptual model is shown in Figure 1. As it can be seen, the main section of DSGE method is optimizing economic forces utility, production or policies. So the mixing of Islamic principles should be done here. Typically, immersing Islamic variables in the household utility function would be different with the household equation in non-Islamic societies. Recognizing the distinctions is the success key here. 


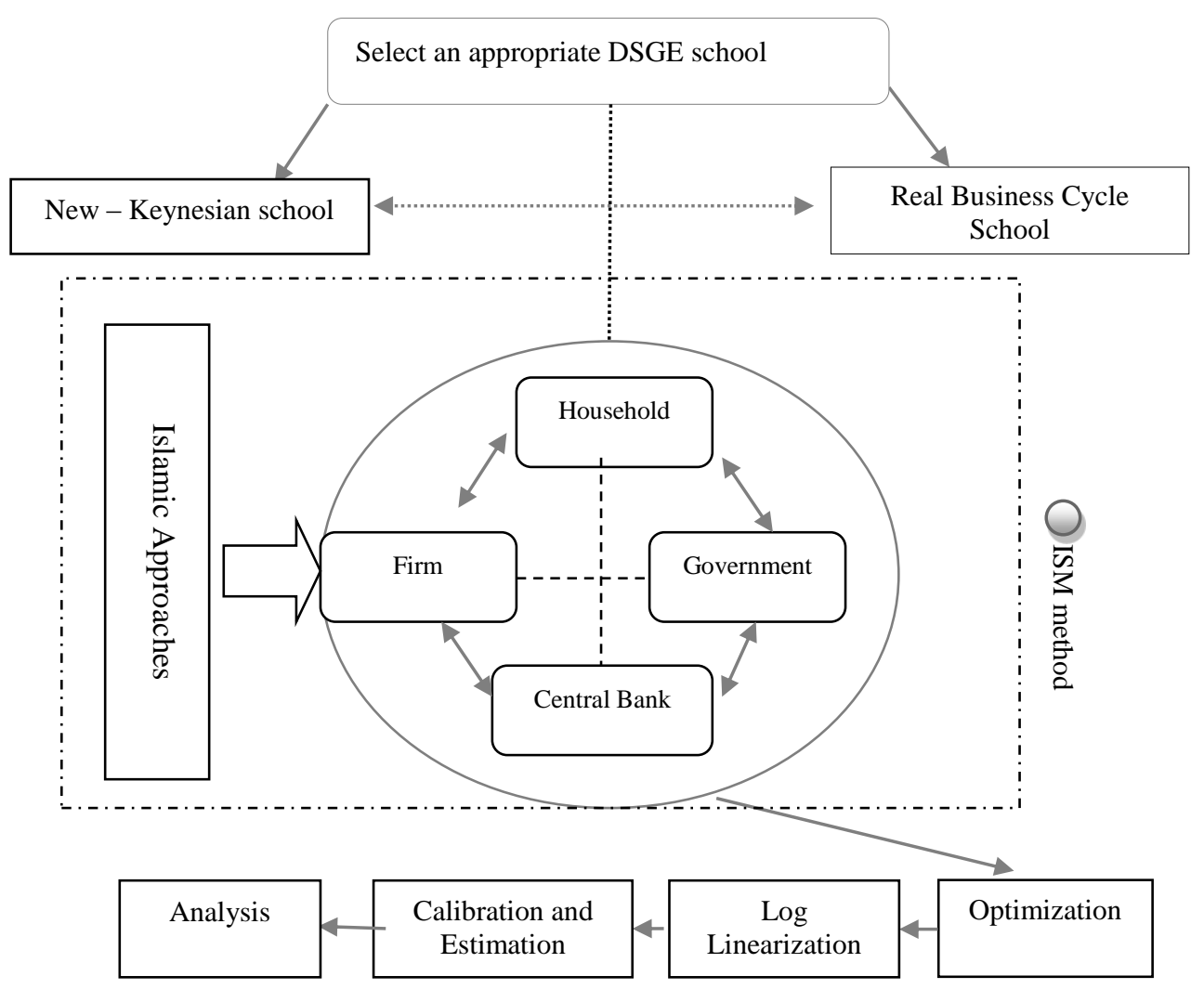

Figure 1. Conceptual model of DSGE.

Our steps for doing the ISM between Islamic principles and DSGE in finance theme which has central bank as the main part of model are as: (i) Identifying factors in each parts of DSGE model according to Islamic principles; (ii) Completing a contextual relationship between elements with respect to which pairs of elements would be examined; (iii) Developing a structural self interaction matrix (SSIM) of elements; (iv) Boosting a reachability matrix from the SSIM; (iiv) Partitioning of the reachability matrix in to different levels; (ixx) Reviewing the model to check for conceptual inconsistency and making the necessary modifications. Based on the above steps, the distinction of elements is recognized and factors of DSGE's parts with Islamic view are determined as shown in Table 1:

Table 1. Islamic principles for DSGE's parts.

\begin{tabular}{|c|c|c|}
\hline \multirow{5}{*}{  } & Parts & Islamic principles \\
\hline & Household (A) & $\begin{array}{c}\text { Care the need of others(A1) } \\
\text { Being God-consciousness (Taqwa) (A2) } \\
\text { Lend capital as loan without interest (Qard-i-Hasan) (A3) } \\
\text { Household doesn't hoard its wealth(A4) }\end{array}$ \\
\hline & Firm (B) & $\begin{array}{c}\text { Care to lower income group(B1) } \\
\text { Spend a portion of capital without any profits (Zakah)(B2) } \\
\text { Efficiency in capital and human resource (Israf)(B3) } \\
\text { Act in a pure comparative markets(B4) }\end{array}$ \\
\hline & Government (C) & $\begin{array}{c}\text { Popular vicegerency(C1) } \\
\text { Common consultation (Shura) (C2) } \\
\text { Dispensation of equitable justice (C3) } \\
\text { Concluding Remarks (C4) } \\
\end{array}$ \\
\hline & Central Bank (D) & $\begin{array}{c}\text { Making monetary policy in base of Sharia law(D1) } \\
\text { Avoiding sinful issues(Harram) (D2) } \\
\text { Surplus value without counterpart (Riba) (D3) } \\
\text { Developing new Islamic methods (Mudharabah or Murabahah) (D4) }\end{array}$ \\
\hline
\end{tabular}


The start point of our research is using experts. Group of experts that includes from universities and research institutions (etc. Research Department of Saderat Bank), were consulted in identifying the nature of contextual relationships among DSGE's parts. For analyzing these parts in developing SSIM, the four symbols as follows have been applied to denote the direction of relationship between parts:

V- Part i will help to obtain part j;

A- Part j will help to obtain part i;

$\mathrm{X}$ - Part $\mathrm{j}$ and $\mathrm{i}$ will help to obtain each other; and $\mathrm{O}$-part $\mathrm{i}$ and $\mathrm{j}$ are unrelated.

The achieved SSIM has been alerted in to a simple matrix which called "Reachability matrix" by replacing $\mathrm{V}, \mathrm{A}, \mathrm{X}$ and $\mathrm{O}$ to 1 and 0 . For instance if the $(i, j)$ entry in the SSIM is $V$, the $(i, j)$ entry in the reachability matrix would be 1 and vice versa the $(\mathrm{j}, \mathrm{i})$ will become 0 .

In the next step, the level of each part is found. These levels will help in designing the diagraph and the final model. The high level part in the structure will not assist to achieve any other part above its own rank.

After ranking the parts of DSGE with the Islamic principles as Government (Level 1), Central bank (Level 2), Firm (Level 3) and Household (Level 4), all 16 Islamic factors can be classified in to four categories as autonomous factors (area zone 1), dependent factors (area zone 2), linkage (area zone 3) and independent ones (area zone 4). We use this kind of classification like Mandal and Deshmukh (1994). The obtained diagram is shown in Figure 2:

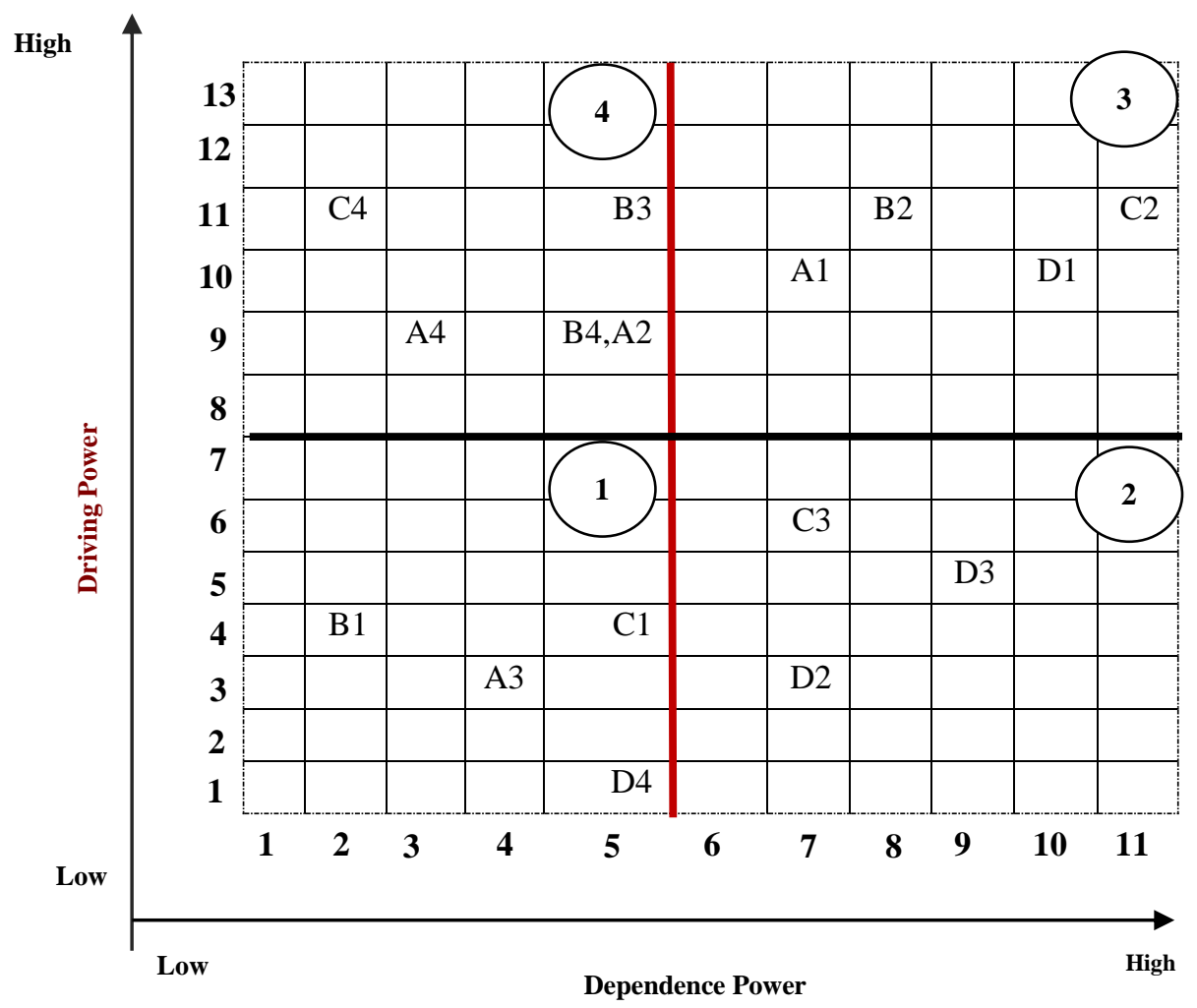

Figure 2. Dependence- Driving Matrix.

It is shown that Islamic factor of C2 (Shura) has a dependence power of 11 and a driving power of 11 and according to this result, it is positioned at a place which called Zone 3 (Linkage variables). About other factors, B1 (care to lower income group) is placed in autonomous area (zone 1) that has a weak driving power and weak dependence power. The factors of this area are relatively disconnected from the system. In our research case, there are 4 autonomous Islamic factors (B1, A3, C1 and D4). The second area is dependent factors which consists weak driving power and strong dependence power. In our research, there are 3 Islamic factors as C3, D2 and D3. The third area zone is called linkage area that has strong driving and dependence power. Any action on these Islamic factors will have an efficient effect on the other factors and also a feedback effect on themselves. A1, B2, D1 and C2 are in this area. The 
fourth area includes independent Islamic factors that have strong driving power and weak dependence power. Here there are C4, A4, B4, A2 and B3.

\section{I-DSGE (Islamic DSGE)}

The logical and structural conceptual model of DSGE under Islamic principles in a financial theme is generated from initial reachability matrix which has ranked factors and parts. We will design an initial directed graph and then it will converted to ISMbased I-DSGE model. This final diagram is the fundamental conceptual model of DSGE which is combined with Islamic principles (Figure 3).

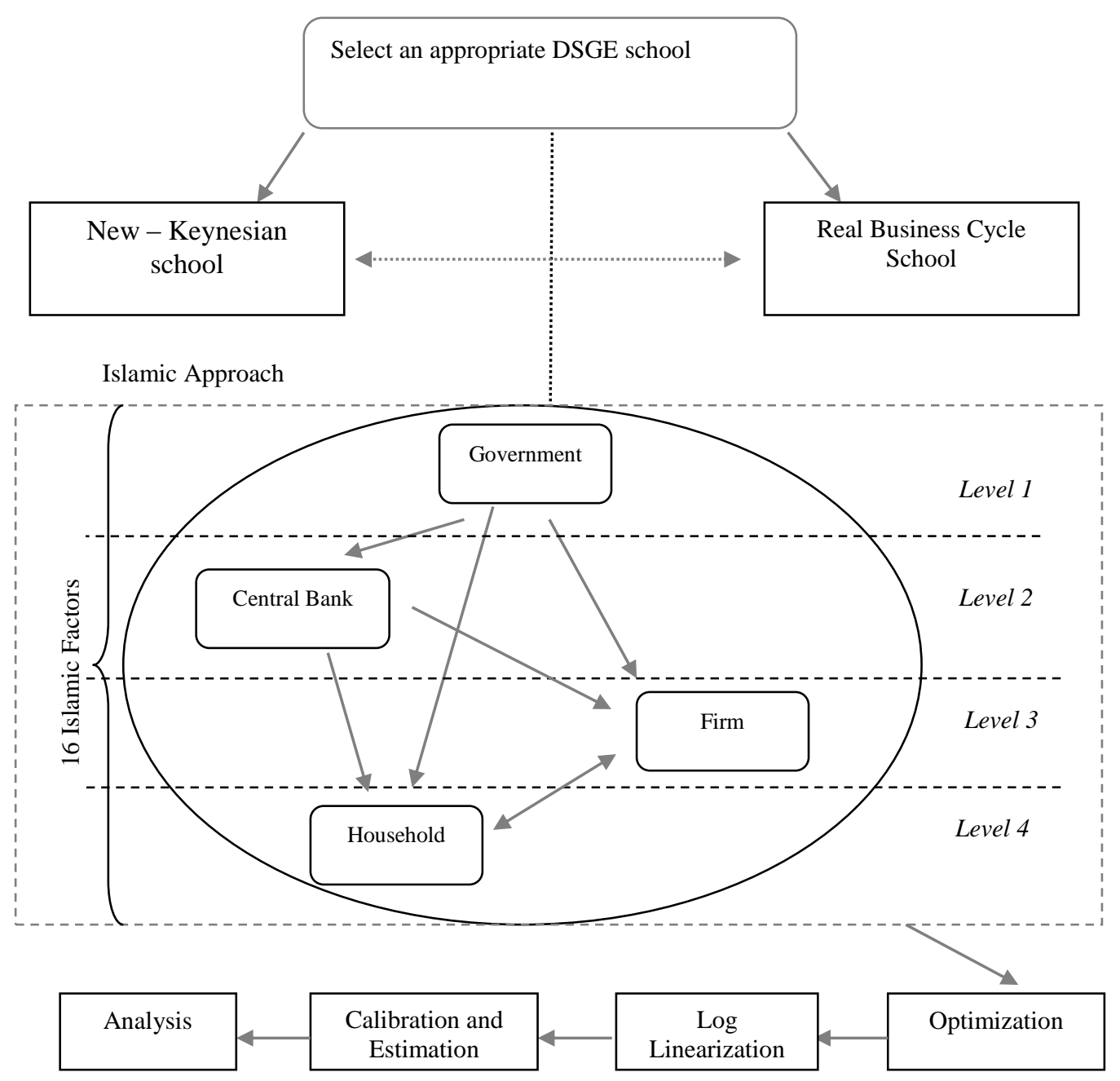

Figure 3. I-DSGE.

\section{Discussion}

As the results showed, the levels of parts and Islamic factors are important in understanding of Islamic DSGE formation and its applicable implementation. The role of government in this level is so essential and important. Government should boost all Islamic factors in its utility functions especially according to Dependent-Driving matrix, Common consultation (C2) and Dispensation of Equitable Justice (C3). So it can be debatable that government is the main part of Islamic behavior of other micro parts of society. Vice versa, household is positioned at the lowest level in the hierarchy of the I-DSGE. The best Islamic factors of this part are Care the need of others (A1), God consciousness (A2) and no-Wealth Hoarding (A4).

Totally about Islamic factors, it is considerable that the factors with highest driving power are "strategic Islamic factors". These factors play a key role in the micro foundation designing of I-DSGE. 
Moreover, they require greater attention in utility functions. Additionally, the Dependence-Driving power matrix gives some valuable and remarkable insights about the relative importance, inner and outer dependencies. This matrix indicates that there is the high portion of factors in the independent area (zone 4).

\section{Conclusion and Future Research Suggestion}

The levels of DSGE parts are important in the success and reality of this model. It can be observed from the results that the rank of these parts through the interpretive structural model (ISM) is Government, Central bank, Firm and Household. Therefore, this rank can be treated in the conceptual model. In all related paper of DSGE this importance haven't been cared and our achieved structure can make all DSGE models purely in Islamic nations become better. Moreover we investigate 16 Islamic factors in these 4 parts. They were classified in four area zone. The mixed version of these factors in the various functions (i.e. utility and production functions) can be applied in the future research to design the micro foundations in base of Islam factors. For example for households, researchers can develop the equation of Islamic consumption model (Fahim khan, 1984) with Askari and Ropele (2009) household utility function as:

$U\left(C, \frac{M}{P}, N\right)=(1-\beta) \sum_{t=1}^{n}\left\{a_{0}+a_{t} * E_{t}\right\}+\frac{m_{i, t}^{1-\delta_{m}}}{1-\delta_{m}}-\frac{N_{i, t}^{1+\delta_{m}}}{1+\delta_{n}}$

Besides this investigation, the Islamic and nonIslamic models comparison would be noticeable. It will show the difference of general equilibrium in Islamic and other worlds. Briefly the suggestions can be presented as the following topics for future researches: (i) Combining Islamic principles with DSGE equations; (ii) Comparing Islamic and nonIslamic economies using DSGE; (iii) Developing Islamic DSGE with futurology or scenario planning; (iv) Mixing I-DSGE with Artificial Neural Networks (ANN); (v) Comparing reactive, inactive and proactive analysis of I-DSGE; (vi) Applying I-DSGE conceptual model in Bond or mortgage market.

\section{References}

Hadavinia A.A, (2006), Possibility, necessity and the standing of Islamic economics (with a comparative view to classic economics), Eghtesad -E- Islamic, 6(23), 51-76.

Gerali A, Neri S, Sessa L, \& Signoretti F (2010). Credit and banking in a DSGE model of the Euro Area, Journal of Money, Credit and Banking, 42 (S1), 107-141.

Mandal A, \& Deshmuck S (1994). Vendor selection using interpretive structural modeling. International Journal of Operations and Production Management, 14 (6), 52-59.

Caldara D, Fernandez J, Rubio J \& Yao W. (2012). Computing DSGE models with recursive preferences and stochastic volatility, Review of Economic Dynamics, 15 (2), 188-206.

Ascari G \& Ropele T. (2009). Disinflation in a DSGE perspective sacrifices ratio or welfare gain ratio. Kiel Working Paper, 14 (99), 63.

Warde I. (2000). Islamic finance in the global economy, Edinburgh University Press, 64-156.

Abdu M \& Azmi M. (2012). Islamic banking and economic growth: the Indonesian experience, International Journal of Islamic and Middle Eastern Finance and Management, 5(1), 35-47.

Fahim Khan M. (1984). Macro consumption functions in an Islamic Framework. Journal of Research Islamic Economics, 1(2), 3-25.

Mosai M. (2011), Inflation and Reba in Islamic economics. International Research Journal of Finance and Economics, 69, 84-94.

Motavaseli M, Bahrami I, Shahmoradi A \& Komijani A. (2011). A new Keynesian DSGE model for an oil exporting country, The Economic Research Journal, 10(4), 87-116.

Taghavi M \& Safarzadeh E. (2009). Optimum rate of money growth in new Keynesian DSGE Framework for Iran economy, Economic Modeling Journal, 3 (9), 77-104.

Villa S \& Yang J. (2011). Financial intermediaries in an estimated DSGE Model for the United Kingdom, Working Paper No.431 Bank of England, 3-29.

Garas S.N. (2012). The conflicts of interest inside the Shari'a supervisory board, International Journal of Islamic and Middle Eastern Finance and Management, 5(2), 88-105.

Azid T. (2010). Anthology of Islamic economics: Review of Some basic issues, Review of Islamic Economics, 13 (2), 165-200.

Nienhaus V. (2010). Fundamentals of an Islamic economic system compared to the social market economy, Kas International Reports, 75-97.

Ahmadali Y. (2010). A comparative analysis of cooperative economics with capitalist and Islamic Economics, Eghtesad E- Islamic, 10 (37), 29-56. 